\title{
Neurolytic effects of ampicillin on the rat infraorbital nerve
}

\author{
Nikola Saulacic ${ }^{1}$, Tommaso Lombardi ${ }^{2}$, Ljiljana Stojcev-Stajcic ${ }^{3}$, Tateyuki Iizuka ${ }^{1}$, Zoran Stajcic ${ }^{4}$ \\ ${ }^{1}$ Department of Cranio-Maxillofacial Surgery, University Hospital, Bern, Switzerland; ${ }^{2}$ Division of Stomatology, Laboratory of Oral \\ and Maxillofacial Pathology, University of Geneva, Geneva, Switzerland; ${ }^{3}$ Clinic of Oral Surgery, Faculty of Stomatology, University \\ of Belgrade, Serbia; ${ }^{4}$ Dental/Medical Center for Maxillofacial Surgery 'Beograd-centar', Belgrade, Serbia
} PURPOSE: The aim of this study was to investigate the
histomorphological changes of the infraorbital nerve of
rats treated with ampicillin.
MATERIALS AND METHODS: The infraorbital nerve
was approached through the infraorbital foramen, and
$0.01 \mathrm{ml}$ of ampicillin dissolved in distilled water was
injected taking care not to damage the nerve. Saline
solution was used in control animals. Nerves were dis-
sected and after routine histology processing analysed by
light microscopy.
RESULTS: Cross-section of the nerve treated with
ampicillin showed damaged axons with disintegration of
heavily myelinated fibres, while thinly myelinated fibres
remain unaffected. In the saline group, no damage was
observed. The signs of regeneration of the damaged
infraorbital nerves were detected on the fourth post-
operative week.
CONCLUSION: Ampicillin can cause peripheral nerve damage when injected perineurally.

J Oral Pathol Med (20I2) 4I: 268-27I

Keywords: ampicillin; infraorbital nerve; rat

\section{Introduction}

Administration of various substances has been demonstrated to reduce the pain-related behaviour after nerve transection in rats. Autotomy phenomenon has been first produced in rodents by axotomy of the sciatic and the saphenous nerves (1). On the nerve stump, neuroma is formed that sends painful impulses to the CNS. As a result of this, animals mutilate the denervated foot. The degree of autotomy is scored from low to high level of mutilation.

Different strategies have been developed to reduce the injury-related pain in the peripheral nerve system.

Correspondence: Dr. Nikola Saulacic, Department of CranioMaxillofacial Surgery, University Hospital, Freiburgsstrasse 10, CH3010 Bern, Switzerland. Tel: +413163 23563, Fax: +41 313820279 , E-mail: nikola.saulacic@insel.ch

Accepted for publication October 11, 2011
Subcutaneous application of oestrogen (2) or testosterone (3), as well as oral administration of Ralfinamide ( $\alpha$-aminoamide derivate) (4), delayed autotomy onset and reduced severity of autotomy scores in peripheral nerve injury rat models. The local administration of myelin-derived inhibitors (Nogo-66 axon growth-inhibiting peptide) significantly lowered the autotomy scores (5). Nerve growth factor decreases the occurrence of autotomy (6), without obvious histological changes observed (7). The emergence of nouvelle biological approaches may offer powerful therapeutic alternative, but mechanistic details are still lacking (8).

It has been previously reported that alcohol, glycerol (9) or even antibiotics (10-12) can decrease or prevent autotomy phenomenon in rodents. A single dose of glycerol causes a significant reduction in autotomy behaviour in rats and is more effective than alcohol (9). Streptomycin injected into the polyethylene tube around the neuroma suppressed autotomy scores up to 8 weeks (12). It has been histologically confirmed that substances such as alcohol $(13,14)$, glycerol (14-18) and streptomycin (19) possess neurolytic properties that were suggested as responsible for the anti-autotomy activity. Nevertheless, neurolysis is not necessarily required to decrease the autotomy onset (7).

It is to be expected that the peripheral afferents blocking would reduce the autotomy phenomenon regardless of the changes in the central nervous system. The peripheral alcohol and glycerol injections are reasonably effective in the management of trigeminal neuralgia (20-23), but demonstrate no substantial benefit over other established gangion-level procedures (24). It has been further demonstrated that some antibiotics combined with anaesthetics can relieve pain in the cranio-facial region $(25,26)$. Still, there is no ready explanation for the mode of action of amoxycillin and ampicillin in prevention of autotomy nor is it known whether they can damage the peripheral nerve when injected perineurally.

The aim of the present study was to investigate the effects of injected ampicillin on the infraorbital nerve of rats. 


\section{Materials and methods}

This study was conducted in concordance with the guidelines of the Ethics Committee of the International Association for the Study of Pain. An official approval was obtained from the Ethical Committee, Faculty of Stomatology, University of Belgrade, Serbia.

Twenty-four albino rats of Wistar strain, of both sexes, weighing between 200 and $300 \mathrm{~g}$ were used for the experiment. Of those, 18 rats were treated with ampicillin $(0.5 \mathrm{~g}$ dissolved in $1 \mathrm{ml}$ of distilled water, Pentrexyl ${ }^{\circledR}$; ICN Galenika, Belgrade, Serbia), and six served as control where sterile saline was injected. The animals were anaesthetised with Nembutal $1 \mathrm{ml} / \mathrm{kg}$ administered via an intraperitoneal injection. $0.01 \mathrm{ml}$ of investigated substances was injected using the 27-gauge needle and tuberculin syringe $1-2 \mathrm{~mm}$ into the infraorbital foramen that was exposed surgically. Care was taken to avoid intraneural injection. The needle was kept in place for 1 min to prevent a leakage of the injected substance. Animals were housed in groups of three under standard colony conditions with regard to feeding, day and night cycle and temperature.

At the end of the observation period, animals were killed by aetherisation. Six animals treated with ampicillin were killed 1,3 and 4 weeks following the procedure. All control rats were sacrificed on the first post-operative week. The infraorbital nerve $1 \mathrm{~cm}$ in length was dissected out and divided into two equal parts. The distal part to be used for analysis was immediately immersed in $4 \%$ buffered glutaraldehyde. The tissue was then prepared for histological examination. The specimens were post-fixed with $1 \%$ osmic acid, dehydrated with the series of graded ethanol and embedded in Epon. The semi-thin cross-sections were stained with toluidine blue or paraphenylene and examined by light microscopy.

\section{Results}

Morphological changes of the infraorbital nerve treated with ampicillin were found in 13 of 18 specimens. In the saline-treated group, normal morphological nervous structure was observed in all nerves (Fig. 1A).

\section{First experimental week}

Heavily myelinated fibres were mostly affected. Swelling and disintegration of myelin sheaths were a constant finding. As a result of this, round or oval globules were present. Most of the destroyed nerve fibres were replaced by macrophages with lipid droplets and Schwann cells containing disintegrated myelin. Histopathological changes were evenly distributed in most of the nerve bundles. Lamellated myelin sheath debris was transformed into amorphous globular lipid. Extensive myelin breakdown was detected in toluidine blue sections by foamy macrophages (Fig. 1B). Small-sized myelinated fibres were mainly preserved, while features of mechanical damage were also occasionally present.

\section{Third experimental week}

Gross demyelinisation and axonolysis were present with myelin debris detected in Schwann cells and in foamy macrophages. Globular lipid droplets were observed in the severed nerves. Specimens stained with paraphenilen showed macrophages with disintegrated debris and proliferating Schwann cells that were grouped into the bands of Büngner (Fig. 1C). In those bands, myelinated
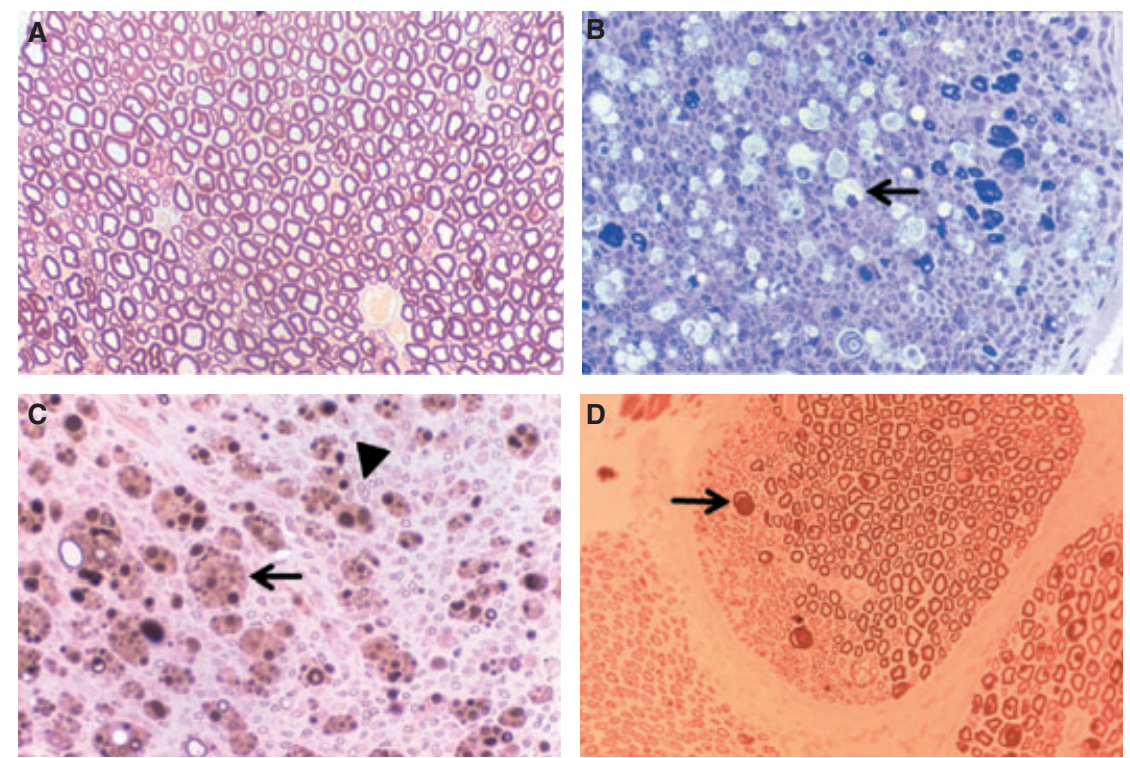

Figure 1 Cross-section of the infraorbital nerve. (A) 1 week following the injection of saline: normal morphological findings (toluidine blue 400:1). (B) 1 week following the injection of ampicillin: destructive changes evenly distributed involving heavily myelinated axons. Macrophages containing lipid droplets are present (arrow) (toluidine blue 400:1). (C) 3 weeks following the application of ampicillin. Small-sized myelinated axons are non-affected (arrowhead), whereas large axons are replaced by bands of Büngner (arrow) as an early sign of regeneration (paraphenilene 400:1). (D) 4 weeks following the application of ampicillin. Signs of regeneration are present in one part of the nerve bundle represented by young axons surrounded by the thin myelin sheaths (arrow) (paraphenilene 400:1). 
fibres with very thin myelin were detected. Small-sized myelinated fibres were unaffected.

\section{Fourth experimental week}

A significant axonal damage was still present. Both axon and myelin debris were largely broken down in cytoplasmic lysosomal vacuoles within the Schwann cells. In half of the specimens, destructive changes were less conspicuous, and nerve fibres undergoing regeneration were surrounded by thin myelin sheaths (Fig. 1D). The features of regeneration were observed as the presence of clusters of 3-4 small myelinated fibres surrounded by the thin myelin sheaths on the fourth post-operative week.

\section{Discussion}

Surgical treatment of trigeminal neuralgia was suggested for patients who fail to respond to first-line medical therapy (27). A number of procedures have been proposed, but these are mainly neurodestructive, and none of them can produce a long-term pain relief. Peripheral procedures should be reserved for patients who have failed medical management or for patients with malignant pain (22-24). Local anaesthetics with streptomycin have demonstrated certain magnitude of effects on severity or frequency of pain (25-28). Besides the reduced autotomy score in rats $(10,11)$, it is questionable whether the local anaethetics combined with ampicillin would be more effective in the treatment of trigeminal neuralgia than anaesthetics alone (29).

In the present study, it was shown that ampicillin when injected perineurally can cause histopathological changes. Injection of ampicillin results in disintegration of the myelinated axons. Different degrees of axonal damage were detected ranging from mild swelling of myelin to complete destruction leading to the absence of lipid droplets. Depletion of Schwann cells may lead to depressed secretion of macrophage chemoattractant protein-1 (30). The macrophage recruitment occurs more intensively after perineural, then intraneural injections, possibly due to the less destructive endoneurial changes (31). Histopathological changes following ampicillin injection were mainly restricted to heavily myelinated axons.

It appears that neural damage caused by application of ampicillin is different from that reported for glycerol, described involving the periphery of the nerve bundle $(14,16-18)$. The perineurium can modify the effects of substances injected perineurally (32). Nerve fibres affected by ampicillin were evenly distributed in most of the nerve bundles, as it has been previously observed for alcohol (13), phenol (18) and strepromycin (19). It can be only speculated that hypertonicity of investigated substances might be responsible for axonal damage.

It has been reported that hypertonic solutions can cause nerve damages such as shrinkage of axons, swelling and fragmentation of myelin (33) mainly because axons contain $90 \%$ water. For the present experiment, highly concentrated $(2.83 \mathrm{osm} / \mathrm{l})$ solution was used. Furthermore, it has been shown that low graded glycerol $(<50 \%)$ does not affect nerve morphology (14). In contrast to streptomycin where both heavily and thinly myelinated fibres were affected (19), ampicillin in the present study caused the desintegration of heavily myelinated fibres. Taking into consideration different pattern of morphological changes caused by ampicillin, glycerol or alcohol, it is possible that the factors other than hypertonicity might be responsible for the neurolytic effects. The selective effect on large myelinised fibres has been demonstrated for certain substances (34-36), but we do not have ready explanation for selective neurolytic properties of ampicillin.

The advantage of perineural injection of phenol and glycerol is the preservation of the basal lamina that provides endoneurial continuity (32). The onset of regeneration of the damaged axons was corresponding to the finding for streptomycin (19). As bands of Büngner cannot be stained by toluidine blue, paraphenilene stain technique was used for this purpose. Early signs of regeneration represented by these bands were noted on the third post-operative week. Regenerative axonal sprouts after glycerol injection may be seen by electron microscopy already at 1 and 2 weeks, although the positively stained targets may indicate axonal sprouts first at 4 weeks (37); the residual morphological changes following neural damage can be observed even after 6 months.

Peripheral surgical treatments are easy to perform, well tolerated, with relatively few serious complications, but have limited duration of action. For certain group of patients, repeatability of the treatment may become an important issue. With regard to suppression of autotomy following the application of ampicillin $(10,11)$, it seems that the described neurolytic property may be responsible for the reduced autotomy. This experiment showed that ampicillin could affect heavy myelinated, but not thin myelinated nerves. Selective depression of large and small fibres may be valuable towards new therapies (8). Still, painful impulse from small fibres can cause pain that can restrain the use of ampicillin in the management of trigeminal neuralgia.

\section{References}

1. Wall PD, Devor M, Inbal R, Schonfeld D, Seltzer Z, Tomkiewicz MM. Autotomy following peripheral nerve lesions: experimental anaesthesia dolorosa. Pain 1979; 7: 103-11.

2. Tsao CM, Ho CM, Tsai SK, Lee TY. Effects of estrogen on autotomy in noram and ovariectomized rats. Pharmacology 1999; 59: 142-8.

3. Li SM, Tsao CM, Tsai SK, Mok MS. Influence of testosterone on autotomy in castrated rats. Life Sci 2002; 70: $2335-40$.

4. Zhang SH, Blech-Hermoni Y, Faravelli L, Seltzer Z. Ralfinamide administrated orally before hindpaw neurectomy or postoperatively provided long-lasting suppression of spontaneous neuropathic pain-related behaviour in the rat. Pain 2008; 139: 293-305.

5. Li L, Qin H, Shi W, Gao G. Local Nogo-66 administration reduces neuropathic pain after sciatic nerve transection in rat. Neurosci Lett 2007; 424: 145-8. 
6. Jubran M, Widenfalk J. Repair of peripheral nerve transections with fibrin sealent containing neurotrophic factors. Exp Neurol 2003; 181: 204-12.

7. Kryger GS, Kryger Z, Zhang F, Shelton DL, Lineaweaver WC, Buncke HJ. Nerve growth factor inhibition prevents traumatic neuroma formation in the rat. J Hand Surg Am 2001; 26: 635-44.

8. Dray A. Neuropathic pain: emerging treatments. $\mathrm{Br} J$ Anaesth 2008; 101: 48-58.

9. Rappaport ZH, Seltzer Z, Zagzag D. The effects of glycerol on autotomy. An experimental model of neuralgia pain. Pain 1986; 26: 85-91.

10. Suaudeau C, de Beaurepaire R, Rampin O, Albe-Fessard D. Antibiotics and morphinomimetic injections prevent automutilation behavior in rats after dorsal rhizotomy. Pain 1989; 5: 177-81.

11. Krsljak E, Stajcic Z. Autotomy phenomenon: experimental model of neuralgic pain. Balk J Stom 1999; 3: 85-8.

12. Stajcic Z. The effects of streptomycin on autotomy. Pain 1992; 48: 257-9.

13. Woolsey RM, Taylor JJ, Nagel JH. Acute effects of topical ethyl alcohol on the sciatic nerve of the mouse. Arch Phys Med Rehabil 1974; 53: 410-4.

14. Rengachary SS, Watanabe IS, Singer P, Bopp WJ. Effects of glycerol on peripheral nerve: an experimental study. Neurosurgery 1983; 13: 681-8.

15. Lunsford LD, Bennett MH, Martinez AJ. Experimental trigeminal glycerol injection: electrophysiologic and morphologic effects. Arch Neurol 1985; 42: 146-9.

16. Pal HK, Dinda AK, Roy S, Banerji AK. Acute effects of anhydrous glycerol on peripheral nerve: an experimental study. Br J Neurosurg 1989; 3: 463-9.

17. Stajcic Z. Effects of glycerol on rat infraorbital nerve: an experimental study. Br J Oral Maxillofac Surg 1991; 29: 90-3.

18. Westerlund T, Vuorinen V, Kirvelä O, Röyttä M. The endoneureal response to neurolytic agents is highly dependent on the mode of application. Reg Anesth Pain Med 1999; 24: 294-302.

19. Stajcic Z, Saulacic N, Dozic S. Effects of streptomycin on the rat infraorbital nerve. J Craniomaxillofac Surg 2002; 30: $304-7$.

20. Rushton JG. Medical treatment of trigeminal neuralgia. With a note on the results of alcohol injection. Med Clin North Am 1968; 52: 797-800.

21. Fardy MJ, Zakrzewska JM, Patton DW. Peripheral surgical techniques for the management of trigeminal neuralgia-alcohol and glycerol injections. Acta Nerochirur 1994; 129: 181-4.

22. Willkinson HA. Trigeminal nerve peripheral branch phenol/glycerol injections for tic douloureux. J Neurosurg 1999; 90: 828-32.

23. McLeod NM, Patton DW. Peripheral alcohol injections in the management of trigeminal neuralgia. Oral Surg
Oral Med Oral Pathol Oral Radiol Endod 2007; 104: $12-7$.

24. Peters G, Nurmikko TJ. Peripheral and gasserian ganglion-level procedures for the treatment of trigeminal neuralgia. Clin J Pain 2002; 18: 28-34.

25. Stajcic Z, Juniper RP, Todorovic L. Peipheral streptomycine/lidocain injections versus lidocaine alone in the treatment of idiopathic trigeminal neuralgia. A double blind controlled trial. J Craniomaxillofac Surg 1990; 18: 243-6.

26. Kreiner M. Use of streptomycin-lidocaine injections in the treatment of the cluster-tic syndrome. Clinical perspectives and a case report. J Craniomaxillofac Surg 1996; 24: 28992.

27. Gronseth G, Cruccu G, Alksne J, et al. Practice parameter: the diagnostic evaluation and treatment of trigeminal neuralgia (an evidence-based revise): report of the Quality Standard Subcommittee of the American Academy of Neurology and the European Federation of Neurological Societes. Neurology 2008; 71: 1183-90.

28. Bittar GT, Graff-Radford SB. The effects of streptomycin/lidocaine block on trigeminal neuralgia: a double blind crossover placebo controlled study. Headache 1993; 33: $155-60$.

29. Vlassakov KV, Narang S, Kissin I. Local anestheic blockade of peripheral nerves for treatment of neuralgias: systematic analysis. Anesth Analg 2011; 112: 1487-1493.

30. Toews AD, Barrett C, Morell P. Monocyte chemoattractant protein-1 is responsible for macrophage recruitment following injury to sciatic nerve. J Neurosci Res 1998; 52: $260-7$.

31. Westerlund T, Vuorinen V, Röyttä M. Some axonal regeneration rate after different endoneureal response to intraneureal glycerol and phenol injection. Acta Neuropathol 2001; 102: 41-54.

32. Westerlund T, Vuorinen V, Röyttä M. The perineurium modifies the effects of phenol and glycerol in rat sciatic nerve. Acta Neuropathol 2004; 108: 319-31.

33. King JS, Jewett DL, Sundberg HR. Differential blockade of cat dorsal root C-fibres by various chloride solutions. J Neurosurg 1972; 36: 569-83.

34. Schröder JM, Gibbels E. Unmyelinated nerve fibres in senile nerves and in late thalidomide neuropathy: a quantitative electron microscopic study. Acta Neuropathol 1977; 39: 271-80.

35. McCredie J, North K, de Longh R. Thalidomide deformities and their nerve supply. J Anat 1984; 139: 397410.

36. Xu Y, Sladky JT, Brown MJ. Dose-dependent expression of neuronopathy after experimental pyridoxine intoxication. Neurology 1989; 39: 1077-83.

37. Westerlund T, Vuorinen V, Röyttä M. The effect of combined neurolytic blocking agent $5 \%$ phenol-glycerol in rat sciatic nerve. Acta Neuropathol 2003; 106: 21-70. 